\title{
Circunstâncias da Cartografia no Brasil oitocentista e a necessidade de uma Carta Geral do Império
}

\author{
Circumstances of Cartography in Brazil during $19^{\text {th }}$ century \\ and the necessity of a National Map of the Brazilian Empire
}

\author{
BRUNO CAPILÉ \\ Museu de Astronomia e Ciências Afins | MAST \\ MOEMA DE REZENDE VERGARA \\ Museu de Astronomia e Ciências Afins | MAST
}

\begin{abstract}
RESUMO Na década de 1860, diversas iniciativas cartográficas foram organizadas em torno do recém-criado Ministério da Agricultura, do Comércio e das Obras Públicas. Mesmo com a presença de instituições e funcionários militares, a criação dessas empreitadas simbolizou a crescente necessidade de conhecimento do território pelo governo imperial. O presente trabalho visa refletir sobre estas iniciativas cartográficas, e de que modo os agentes da época buscaram confeccionar mapas mais adequados às estratégias administrativas e de representação de uma imagem territorial, que culminou com a Carta Geral do Império publicada em 1875 e 1876.
\end{abstract}

Palavras-chave História da Cartografia - Ministério da Agricultura - Carta Geral do Império.

\begin{abstract}
In 1860's several cartographical initiatives were organized around the newbie Ministério da Agricultura, do Comércio, e das Obras Públicas (Ministry of Agriculture, Trade and Public Works). Even with the presence of military institutions and officials, the creation of these works symbolized the increasing need of territorial knowledge by the imperial government. This work aims to reflect on these cartographical initiatives and how the agents of the period sought to produce maps best suited to administrative and territorial representation strategies, which culminated in the Carta Geral do Império (General Chart of the Empire) published in 1875 and 1876.
\end{abstract}

Keywords history of Cartography - Ministry of Agriculture - General Charter of the Brazilian Empire.

Todo mapa é o produto de diversos processos envolvendo diferentes indivíduos, técnicas e ferramentas. ${ }^{1}$

A Carta Geral do Império foi publicada na década de 1870, e tornou-se uma das melhores referências cartográficas do Brasil Império produzida pela Comissão da Carta Geral do Império (CCGI). Foi no Segundo Reinado que ocorreu um conjunto de iniciativas interconectadas que estavam sob a égide do Ministério da Agricultura, do Comércio, e das Obras Públicas (MACOP). As iniciativas cartográficas do período foram: Comissão de Triangulação do Município Neutro (1866); Comissão da Carta Itinerária (1874); Comissão Geológica (1875); Comissão Astronômica (1876); a Comissão da 
Carta Arquivo (1876); e a Comissão da Carta Geral do Império (1862). ${ }^{2} 0$ presente texto aborda estas comissões e suas relações, e como que a versão do mapa nacional da Carta Geral do Império tornou-se "a melhor por nós possuída por quase meio século", sendo equiparada somente à Carta Geral da República de 1922, realizada pelo Clube de Engenharia do Rio de Janeiro. ${ }^{3}$ A pluralidade de agentes na produção cartográfica no Brasil Imperial é um dos fatores que dificultam a construção de uma narrativa linear para a interpretação deste processo. Ao enfrentar estes obstáculos, é possível construir um quadro preliminar, estabelecendo os membros da Comissão da Carta Geral do Império (CCGI), como ela estava organizada, seus métodos, produtos e a circulação dos mesmos. Neste sentido, iremos trazer, para a História da Ciência, um tema tradicionalmente estudado na esfera das relações exteriores, ou seja, a Cartografia, e, assim, ampliar as discussões sobre as atividades científicas que estavam se desenvolvendo no Brasil do século XIX. Apesar de parecer autoevidente, é importante esclarecer para os leitores que os mapas nacionais possuem tanto a função de estabelecimento de seus limites como de conhecimento do aspecto geográfico de seu território. Esta ressalva se justifica, uma vez que essas atividades de mapeamento e delimitação são correlatas, mas não podem ser vistas como sinônimos.

Ao considerar os mapas como fontes históricas, devemos ter em mente que estes podem ter uma série de intenções por trás da representação gráfica das linhas e relevos. No que tange a reflexão histórica dos mapas e seus significados, é pertinente resgatar as discussões de John Harley. Segundo ele, os mapas "fazem parte de um discurso persuasivo, e pretendem convencer", ${ }^{4}$ sendo a maioria deles direcionada para um público específico e dotada de argumentos de autoridade usados por quem investiu na realização do mapa. Este possui necessidades externas a ele, e se torna uma ferramenta para a manutenção do poder governamental para gerenciar suas fronteiras, comércio, administração interna, controle de populações e força militar, através de um discurso social, ideológico e retórico. Nessa concepção, o mapa é uma construção social que não é neutra e seu estudo possibilita uma descrição do mundo, considerando relações de poder e práticas culturais, preferências e prioridades de seus agentes.

Para Harley, a regra básica da abordagem histórica dos mapas é que esses devem ser interpretados a partir de seu contexto, como um panorama histórico geral que resgata o local e o momento específico da produção do mapa em questão. Dessa forma, Harley nos instiga a buscar as intenções e circunstâncias que permeavam a produção e a publicação cartográfica. “Como uma expressão de intenção, função torna-se uma peça-chave para ler os mapas, mas tais intenções são geralmente pouco definidas, ou os mapas podem ser direcionados para mais de um leitor". ${ }^{5}$ Através desse contexto, distinguiremos alguns aspectos básicos que tornam possível interpretar suas intenções, a partir dos possíveis interesses de quem mandou fazer o mapa, no caso, o governo imperial. Logo, para este estudo, voltamos nossa atenção para a Carta Geral do Império e suas relações com as comissões paralelas que estavam centralizadas sob a direção do Ministério da Agricultura.

\section{Nação e território: os interesses cartográficos}

Na década de 1840 podemos localizar os primeiros trabalhos de demarcações de fronteiras com os países vizinhos, como Guiana Inglesa (1843), Uruguai (1853-1862), Peru (1864), Bolívia (1871-1874), Venezuela (1879), Argentina (1885-1886), contribuindo para a necessidade de construção de uma carta nacional. Na medida em que o Império consolidava a conquista de territórios e de suas fronteiras, tornava-se necessário configurar um mapa completo que pudesse estruturar os aspectos do espaço e do território, e definir por meios cartográficos a posição do país como uma nação civilizada e próspera. Nesse momento, constatamos a elaboração de mapas nacionais como os de Conrado Jacob Niemeyer (1846) e de Candido Mendes de Almeida (1868). ${ }^{6}$

Paralelo ao processo de estabelecimento dos limites internacionais é importante destacar o surgimento do Ministério da Agricultura, em 1860. Este foi um reforço emblemático na integração territorial do Brasil. Na medida em que 0 uso da terra para o cultivo agrícola se expandia para o interior, via-se a necessidade do acesso a esses terrenos através de vias férreas, fluviais e convencionais. Nesse sentido, o governo imperial convergiu esses interesses em uma 
instituição, o Ministério da Agricultura, do Comércio, e da Obras Públicas (MACOP), que era dividido em quatro diretorias internas: Central e dos Negócios da Agricultura, Comércio e Indústria, voltada para as atividades econômicas propriamente ditas; das Obras públicas e Navegação, relacionada a obras não-militares, criação e manutenção de vias, os telégrafos e iluminação; das Terras Públicas e Colonização, que também incluía as catequeses e a "civilização" dos índios; e dos correios. ${ }^{7}$ Dessa forma, o governo institucionalizou vitais atividades que se referem à administração do território.

Mesmo escassos, os trabalhos cartográficos eram fundamentais para o funcionamento do Ministério, que, em 1862, contava com quatro desenhistas e um agrimensor que realizaram cópias de mapas, projetos de obras e plantas. Segundo os engenheiros Werneck e Krauss, que atuaram na CCGl até 1866, o governo possuía "parco conhecimento" dos recursos, e recomendavam o levantamento de um mapa topográfico, o estudo de vias de comunicação e a exploração a respeito de tudo 0 que envolve a sua agricultura, indústria e comércio. ${ }^{8}$ Para sanar este problema, cabe salientar a iniciativa do governo imperial ao fortalecer a figura do diplomata Duarte da Ponte Ribeiro, que angariou diversos mapas relativos ao território nacional em arquivos dispersos no Brasil, em Portugal e na Espanha.

\section{Os bastidores do mapa de 1876}

Dois grandes conjuntos de problemas deveriam ser resolvidos para a confecção da carta: o primeiro seria uma "inserção no universo conhecido das representações cartográficas", ${ }^{9}$ Cabe lembrar que a compilação de mapas antigos era então uma prática largamente utilizada. 0 passo inicial seria o aproveitamento de mapas gerais ou regionais já existentes. A segunda questão estava relacionada com a "escolha do repertório das tradições das experimentações do território", ${ }^{10}$ ou seja, a determinação do método a ser empregado. Eram de notório conhecimento os possíveis equívocos de mapas antigos, neste sentido, sendo fundamental o aproveitamento pela CCGI dos dados de outras comissões científicas contemporâneas. Um traço que diferenciava a CCGI das comissões anteriores era a disponibilidade de recursos para a realização de atividades de campo, que complementavam os trabalhos de compilação.

A importância em organizar as fontes cartográficas foi assinalada por Ponte Ribeiro, em seu livro Exposição dos trabalhos históricos, geográficos e hidrográficos que serviram de base à Carta Geral do Império exibida na Exposição Nacional de 1875 (1876). Nesta obra, Ponte Ribeiro afirmava que esta publicação "terá a dupla conveniência de fazer conhecer por a existência desses importantes trabalhos, e de facilitar aos competentes a apreciação da Carta Geral do Império". "Ponte Ribeiro localizou 330 trabalhos; deste montante constavam mapas da parte setentrional do país relativos ao Tratado de São Ildefonso; mapas das partes ocidental, meridional, oriental e central e somente 9 mapas representando o país inteiro. Este conjunto, em sua grande maioria, pertencia ao Archivo Militar e ao Ministério dos Negócios Estrangeiros.

A publicação desta obra de Ponte Ribeiro influenciou em muito o marechal Henrique Beaurepaire Rohan, ${ }^{12}$ chefe da CCGI, a realizar a Comissão da Carta Archivo, que deveria organizar cartas especiais das províncias com o intuito de complementar e retificar as folhas da Carta Geral e a prestação de pareceres, informações, cópias de plantas e documentos exigidos pelo Ministério da Agricultura. Nessa intenção de reunir o maior número possível de dados para o completo desenvolvimento da carta arquivo, Beaurepaire Rohan pede em ofício de 3 de Julho de 1876 para que as províncias fornecessem informações sobre os respectivos rios e relevos. No entanto, das vinte províncias, somente dez retornaram os dados requisitados (Pará, Piauí, Ceará, Paraíba do Norte, Pernambuco, Bahia, Espírito Santo, Rio Grande do Sul, Goiás e Mato Grosso)..$^{13}$

Além do uso de mapas antigos, que por vezes continham equívocos de confecção ou de reprodução, as comissões configuravam ótima ferramenta para complementação e conserto. Devido ao interesse em mapear a capital para solução de problemas e melhoramentos urbanos, a Comissão de Triangulação do Município Neutro foi criada em 1866 e depois incorporada a CCGI em 1870. Ambas surgiram na Inspeção Geral das Obras Públicas do MACOP, sendo a Comissão de Triangulação importante para suprimir a necessidade de se ter um mapa topográfico apurado da Corte e 
sem erros para a organização de uma planta geral demonstrativa de todos os mananciais de águas aproveitáveis e por aproveitar, o que consistia numa das funções da referida Inspeção. 0 diálogo dessas instituições foi de vital intercâmbio de informações geodésicas. Nos trabalhos da triangulação da capital incluiu-se, também, a realização da Planta Cadastral, que tinha como objetivo registrar os edifícios que existiam, mesclando este dado com o dos mananciais de forma a explorar melhor o uso dos recursos hídricos.

A respeito dos trabalhos da Comissão de Triangulação, Beaurepaire Rohan afirmou que "a triangulação feita em 1868 pode-se considerar perdida", por defeito do basímetro e dos sinais geodésicos que foram utilizados. ${ }^{14}$ Apesar de seus equívocos na triangulação, aqueles trabalhos tinham, segundo Beaurepaire Rohan, a finalidade de servir de escola prática para os engenheiros e alunos da Escola Politécnica, antiga Escola Central.

Sempre considerei a triangulação do município da corte não só em seu destino especial - o levantamento exato da planta, e em seguida a construção da carta cadastral do município, como também a reputei sempre a melhor escola prática que poderíamos oferecer aos nossos jovens engenheiros geógrafos. ${ }^{15}$

Dentre a interação com as demais comissões, vale destacar a Comissão Geológica. Em 1873, o Ministério já reconhecia a necessidade de uma Carta Mineralógica que localizasse as minas conhecidas e as concessões de exploração feitas pelo governo. Nesse momento ainda não havia uma iniciativa geológica de abrangência nacional. 0 empreendimento iria suprir, também, com conhecimentos sobre as terras cultiváveis, as possibilidades para assentamentos de novas colônias e a acessibilidade para estas. Em 1875, o geólogo americano Charles E. Hartt (1840-1878) desenvolveu essa ideia, e submeteu ao Imperador Pedro II a proposta de realizar um reconhecimento geológico no país, o qual seria nomeado de Comissão Geológica do Império. Uma leitura rápida dos relatórios ministeriais podem nos levar a crer que a proposta foi feita pelo Ministério da Agricultura para Hartt. No entanto, foi ele que sugeriu a ideia de realização de um serviço geológico no império. ${ }^{17}$ Os interesses do ministério iriam, depois, nomear os integrantes da Comissão da Carta Geológica, a qual seria responsável pela descrição de estudo da estrutura geológica; paleontologia e paleobotânica; minas diversas; exame químico das rochas; elevação relativa; variações de clima; caráter e extensão das matas e dos campos; agricultura; animais úteis e nocivos; arqueologia; etnologia; amostras e fotografias; e pelo levantamento de uma carta geológica.

Já a Comissão da Carta Itinerária, pode ser vista como uma iniciativa que forneceu os antecedentes necessários para a CCGI, contando com parte de seus membros, e aquela "devia compreender não só as vias de comunicação existentes, como a indicação topográfica dos lugares que se prestem ao traçado de novas [vias]". ${ }^{18}$ A Comissão da Carta Itinerária iniciou seus serviços em julho de 1875, e era composta por Beaurepaire Rohan, Guilherme de Capanema, Manuel Buarque de Macedo, e por cinco engenheiros. Devido à dificuldade na escolha desses engenheiros, o Ministro da Agricultura José F. C. Pereira Jr. decide contratar para este serviço, como auxiliares, engenheiros austríacos. Estes passaram a trabalhar na Comissão da Carta Geral após o fim de sua comissão original em junho de 1878. 0 intuito da comissão era iniciar seus trabalhos geodésicos e topográficos na província do Rio Grande do Sul e seguir para a direção Norte entre os meridianos $7^{\circ}$ e $9^{\circ}$ do Rio de Janeiro. A comissão conseguiu concluir, assim, uma carta topográfica de Porto Alegre, uma carta itinerária, plantas especiais das estradas, e uma carta geológica da zona entre os rios dos Sinos e Guaíba, incluídas as serras do Pinhal, Santana e a bacia do Gravataí, no Rio Grande do Sul.

A Comissão Astronômica, criada em fevereiro de 1876, tinha como objetivo determinar as posições geográficas dos pontos da estrada de ferro de Dom Pedro Il da corte à Província de São Paulo. Chefiada pelo astrônomo Manoel Pereira Reis (1837-1922) e auxiliada por Fábio Hostílio de Moraes Rego (1849-1917), a Comissão Astronômica teve sua importância direta à Carta Geral do Império reconhecida por Beaurepaire Rohan. Através desses pontos geográficos, resultou na medição e conhecimento perfeito de um arco de paralelo, ligando a capital do Império ao grande meridiano do Brasil. Este meridiano segue da barra do Chuí à fronteira da Guiana Francesa, com aproximadamente 38 graus de latitude de comprimento. ${ }^{19}$

Para a determinação da longitude desses pontos da estrada de ferro, foram utilizadas as linhas telegráficas ${ }^{20}$ da mesma via, assim como as do cabo submarino para a determinação das longitudes do Imperial Observatório com a 
Europa e a América do Norte. Na ausência de linhas telegráficas, estava previsto utilizar o sistema de sinais luminosos ${ }^{21}$ elaborado conforme um plano novo adotado pelo Imperial Observatório. De fato, Emmanuel Liais (1826-1900) confirmou que esse sistema é "mais exato do que o emprego dos fios telegráficos". Nesse anexo de ofício enviado para a Diretoria de Obras Públicas, Liais explicou que

\begin{abstract}
Consiste o processo em estabelecer nas estações intermediárias, que se acharem entre os pontos extremos cuja diferença de longitude se quer conhecer, relógios de marcha diferentes, e que transmitem sinais luminosos, correspondentes a cada pancada de segundo. Estes sinais são dados pela eletricidade, e a mesma correnteza que os fornece estabelece rigorosamente no mesmo instante uma abertura num diafragma especial e opaco duma luneta, de modo que são visíveis na outra estação. Neste caso, a pancada de cada segundo na primeira estação, que coincide com a pancada de segundo na outra estação, dá lugar à aparição de um sinal luminoso. ${ }^{22}$
\end{abstract}

No relatório da Comissão Astronômica, Determinação das diferenças de latitude e longitude entre o Imperial Observatório Astronômico do Rio de Janeiro e a Barra do Pirahy, publicado em 1877, Reis descreve as técnicas e os instrumentos utilizados nas determinações de longitude efetuadas pela comissão durante essa $1^{\text {a }}$ operação. A longitude determinada pela telegrafia realizou-se por meio de três séries de observações, na primeira, colocou-se 0 cronógrafo elétrico na Barra; na segunda foi este transferido para o Rio de Janeiro, e revezaram-se os observadores; e na terceira, finalmente, conservando-se ainda o instrumento nesta corte, os observadores tomaram a posição que ocuparam na primeira série. As observações seguiram um sistema desenvolvido por Liais que utiliza um cronógrafo elétrico, que serve para registrar o momento em que foram executadas as observações astronômicas. ${ }^{23}$ Cabe registrar que a nomeação de Pereira Reis para a chefia desta comissão foi indicada pelo próprio diretor do Observatório em 1878. Contudo, por divergências na execução do trabalho, no âmbito da Comissão Astronômica, o primeiro foi exonerado do Imperial Observatório, gerando polêmicas sobre o cálculo da longitude. Isto também significou o desligamento temporário do Observatório com os trabalhos da Carta do Império. ${ }^{24}$

De acordo com os objetivos apresentados pelo Ministério da Agricultura, essas comissões contribuiriam para satisfazer diferentes interesses, não somente dados para um mapa do país. Os mapas da Comissão Geológica forneceriam conhecimentos sobre os terrenos cultiváveis e não cultiváveis, do ponto de vista geológico do solo, e de relevo; a Carta Itinerante contribuiria também com a topografia do terreno para construir novas vias, assim como a futura construção destas para o escoamento dos produtos agrícolas; a comissão que não gerou mapas foi a astronômica; no entanto, rendeu dados e coordenadas geográficas que auxiliaram a Carta Geral do Império.

Nas últimas décadas, a historiografia sobre ciência no Brasil abandonou a tendência a considerar a intermitência das iniciativas científicas como um desinteresse do governo imperial, ou como prova da inaptidão científica brasileira. No entanto, a falta de continuidade destes trabalhos pode ser atribuída às dificuldades econômicas, políticas e sociais do Império: A Guerra do Paraguai, as crises agrícolas, o eminente fim da escravidão, a insatisfação com a figura do Imperador, ou até mesmo a morte do Barão da Ponte Ribeiro no ano de 1878. Do ponto de vista do MACOP, as comissões foram todas desmanteladas devido a razões financeiras.

\footnotetext{
Sem desconhecer o alto valor científico de semelhantes trabalhos, alguns indispensáveis ao levantamento da Carta Geral do Império, e, por outro lado, reconhecendo a provada aptidão e o zelo, assim do chefe como dos auxiliares da comissão, tenho, todavia, deliberado dissolve-la, por que assim o exigem as circunstâncias financeiras. ${ }^{25}$
}

Devido à participação de membros em comum, a CCGI manteve um vínculo maior, apesar das relações tempestuosas, com a Comissão Astronômica e com o Imperial Observatório do Rio de Janeiro. Em relação à metodologia, a Carta do Império deveria ser produzida a partir da projeção cartográfica de Flamstead, o meridiano inicial a partir do Pão de Açúcar e a escala de 5 milímetros o minuto do Equador. 0 Relatório da CCGI de 1875 explicava "a razão de se 
tomar o meridiano do Pão de Açúcar" ${ }^{26}$ Isto ocorreu devido ao fato de o Observatório estar situado no Morro do Castelo, cujo arrasamento já estava decretado pelo Governo Imperial. A mudança daquela instituição aconteceria somente em 1921 para o Morro de São Januário, em São Cristóvão.

A astronomia e a geodésia, conhecimentos inerentes à prática cartográfica, estavam intimamente vinculadas à existência de um observatório astronômico. No regulamento de 1846 do Observatório, este deveria realizar as observações astronômicas e meteorológicas úteis à ciência e publicá-las junto com 0 extrato das melhores efemérides estrangeiras; formar os alunos da Escola Militar nas técnicas geodésicas e os alunos da Academia da Marinha nas técnicas de navegação, entre outras funções. ${ }^{27}$ Apesar da existência de uma instituição que deveria formar técnicos para execução de trabalhos geodésicos, Beaurepaire Rohan apontava a falta de profissionais, aliada as proporções continentais do país, como fatores para justificar a lentidão da CCGl em finalizar o mapa. Este comparou os trabalhos da carta da França no século XVIII com as atividades ocorridas no Brasil. Ao equiparar as superfícies quadradas de ambos os países, supôs somente ser possível a realização da Carta Geral do Império em 800 anos, ou em 50 anos com um pessoal dezesseis vezes maior. ${ }^{28}$ Para a construção da Carta Nacional era necessário, segundo Werneck e Krauss, a uniformização do serviço por meio de regulamentos claros e detalhados, de forma a minimizar os erros derivados das transformações. A estabilidade e continuidade do serviço, e a regulação da remuneração dos trabalhos de exploração figuram como itens incentivadores à realização das atividades. E finalmente, os resultados obtidos deveriam ter a maior circulação possível, "para não serem esquecidos em arquivos". ${ }^{29}$

\section{A trajetória da comissão da Carta Geral do Império}

A história da CCGI se divide em três momentos. 0 primeiro, marcado por dificuldades de ordem técnica e administrativa, fator recorrente em instituições científicas do século XIX no Brasil, possuiu poucos registros históricos. Werneck e Krauss organizaram e começaram os trabalhos iniciais da Comissão nos primeiros anos, e Ernesto José Carlos Vallée ${ }^{30}$ fica à frente da chefia da organização de 1864 até dezembro de 1872.0 governo imperial ainda não apresentava administração estabilizada e nem uma seriedade para com as atividades científicas, características que persistiram até os anos iniciais do século XX. Esse modus operandi refletiu em diversas empreitadas em que o país se debruçava, acarretando obstáculos a serem contornados. Na fase inicial da CCGI, os problemas identificados nos relatórios ministeriais eram: a dificuldade em encontrar desenhistas, a suposta baixa produtividade dos engenheiros envolvidos, e a falta de retorno de informações requeridas pelas províncias. Até esses obstáculos serem devidamente contornados, ou destinados ao segundo plano, a Comissão vivenciara uma insuficiência das atividades cartográficas. No entanto, mesmo com a deficiência dos dados geográficos e a raridade de documentos oficiais antigos, a comissão conseguiu reunir grande soma de documentos, com os quais tem dado aos trabalhos o impulso possível. Este agrupamento de documentos se deu pelos esforços pessoais de Ernesto Vallée e de Ponte Ribeiro, assim como de algumas comissões internas organizadas para a obtenção de dados das províncias que não conseguiram fornecer. Em relatório do MACOP constava que

As circunstâncias da atualidade não comportam medidas mais eficazes para se obterem os elementos necessários a este importante serviço; oportunamente dever-se-ão nomear comissões especiais compostas de engenheiros habilitados, as quais serão incumbidas de colher nas províncias os esclarecimentos precisos. ${ }^{31}$

Estas comissões tinham o objetivo de obter informações de pontos menos conhecidos ou de cujas posições astronômicas faltavam documentos oficiais e autênticos, como a executada por Francisco Manoel Álvares Araújo, condutor do vapor Saldanha Marinho pelo rio das Velhas até o de São Francisco, que também foi incumbido de estudos no sudoeste da Bahia e ao norte de Minas Gerais; João Martins da Silva Coutinho, ${ }^{32}$ na província de São Paulo; e pelo João Nunes de Campos às províncias do Rio Grande do Norte, Paraíba, Pernambuco, Sergipe e ao Norte da Bahia. ${ }^{33}$ 
Reconhecidas as referidas dificuldades, assim como a importância da conclusão da Carta Geral, o ministro Diogo Velho Cavalcanti de Albuquerque afirma que é "da mais alta conveniência apressar a publicação de trabalhos desta natureza", e requisita "uma consignação especial para as despesas da impressão da carta geral do império" ${ }^{34}$ Ao longo da história da CCGI, essa não foi a única vez que a finalização do mapa foi apressada. Esse tipo de discurso está relacionado com as informações obtidas nos relatórios ministeriais, que, como era de se esperar, eram feitos de modo a agradar e satisfazer os interesses governamentais. Logo na primeira fase, podemos ver em relatório da Inspeção Geral das Obras Públicas que o governo já estava convencido de que ficariam anos sem ter um mapa exato. No entanto, afirmava que o serviço deveria ter uma reforma radical para ser concluído o mais rápido possível, o que provavelmente comprometeria a qualidade resultante. Essa retórica sobre exatidão e rapidez foi repetida ao longo dos anos nos textos da CCGI. Esta questão parece ter encontrado uma solução na proposta da elaboração de um mapa reduzido à metade da escala adotada originalmente, em 1871. Sendo assim, os trabalhos corretivos das comissões internas poderiam continuar ajudando nos mapas de Província que vinham sendo feitos, "de maneira que até 0 ano de 1884 e 1885 possuirá o Império uma carta que satisfaça todas as exigências administrativas (...)" ${ }^{35}$ Mesmo assim, pode-se perceber que até o final do funcionamento da CCGI o binômio exatidão versus rapidez esteve presente no discurso dos dirigentes que afirmaram que os trabalhos, até então realizados, ainda iriam servir de "base para a organização definitiva da Carta Geral do Império". ${ }^{6}$ Dessa forma, pode se concluir que a publicação de um mapa considerado por Beaurepaire Rohan como "sofrível", ${ }^{37}$ que somente satisfaria todas as exigências administrativas na década de 1880, estaria relacionada principalmente aos aspectos simbólicos de progresso e civilização.

0 segundo momento foi marcado pelo constante acúmulo de função da Comissão por iniciativa dos Ministros da Agricultura. 0 começo se dá na integração, em 23 de maio de 1870, da Comissão da Triangulação do Município Neutro, que, assim como a CCGl, também estava a cargo da Inspetoria Geral das Obras Públicas, conforme dito anteriormente. Dessa forma, o ministro Francisco do Rego Barros Barreto achou "conveniente reunir na comissão incumbida da organização da Carta Geral todos os trabalhos geodésicos". ${ }^{38}$ À medida que os trabalhos se multiplicaram e se acumularam houve a "impossibilidade de continuar a ser feito o serviço nas duas salas do edifício da Inspetoria Geral das Obras Públicas" ${ }^{39}$ Dessa forma, achou-se conveniente alugar um prédio para compartilhar com a comissão de conversão, pesos e medidas para o sistema métrico francês, e com a comissão do Registro Geral de Terras Públicas.

Após a saída de Vallée, em dezembro de 1872, designou-se o engenheiro João Nunes de Campos para substituí-lo interinamente na presidência da Comissão. Nunes de Campos já dera provas de sua aptidão em trabalhos de determinação de pontos astronômicos de comissões internas da própria Comissão da Carta Geral do Império, e na reunião de documentos cartográficos em províncias do Nordeste brasileiro.

Para adequar os trabalhos da Comissão ao contingente de funcionários e aos recursos obtidos, optou-se por seguir as exigências ministeriais e realizar, primeiramente, uma versão reduzida da Carta Geral do Império, utilizando o sistema que o Abbadie descreveu em sua obra Géodésie d'Éthiopie. ${ }^{40}$ A relevância de se terminar os trabalhos de redução da Carta Geral culmina com uma seção exclusiva para tal, criada pelo presidente Dr. Nunes de Campos em 1874 para dar cumprimento ao aviso do Ministério da Agricultura de março de 1874. A versão reduzida, chefiada por Manoel Pereira Reis, utilizou a projeção de Flamstead modificada para elaborar a carta de 1,260 m de largura por 1,193 m de altura, numa escala de 1:3.710.220, que correspondia à metade do tamanho da versão que eles queriam para o original; e foi publicada na Exposição Nacional de 1875 e na Exposição Universal de Filadélfia de 1876, elaborada por "Henschel \& Benque (...), empregando-se, para isso, o processo foto-litográfico" . ${ }^{41}$

0 terceiro e último momento caracterizou-se pela entrada de Beaurepaire Rohan (1874-1878) após a morte de Nunes de Campos em 27 de setembro de 1874, sendo o momento de publicação dos resultados. Apesar de o chefe interino da seção da Carta Geral, Fábio Hostílio de Moraes Rego, ter afirmado que a carta "apresentava erros gravíssimos, em desacordo completo com os documentos existentes no arquivo da comissão", a versão final foi bem recebida. ${ }^{42}$

No momento em que a carta reduzida era finalizada, em meados de 1874, achava-se a comissão com 25 pessoas, divididas em quatro seções, o maior contingente de funcionários vivenciado até então. A seção da Carta Geral tinha 
como chefe Manoel Pereira Reis, e quando esse viajava pela Comissão Astronômica, Fábio Hostílio de Moraes Rego 0 substituía; a seção de Triangulação era chefiada por José Manoel da Silva; a seção de Redução para a Exposição da Filadélfia; e diversos na seção de trabalhos de escritório, dentre eles Carlos Lemaire Teste, responsável pela resolução de problemas geodésicos, que escreveu uma obra sobre nivelamento (Estudo de níveis, de 1878), além de desenhistas, um copista, um praticante de escrituração e um contínuo. 0 astrônomo belga Luiz Cruls, que fora diretor do Observatório entre os anos de 1882 e 1908, também participou da CCGI, sendo um de seus primeiros trabalhos quando ingressou naquela instituição, em 1874. Ele trabalhou na seção de geodésia e fora responsável pela compra de instrumentos científicos na Europa para a CCGI.

\section{A Carta Geral do Império}

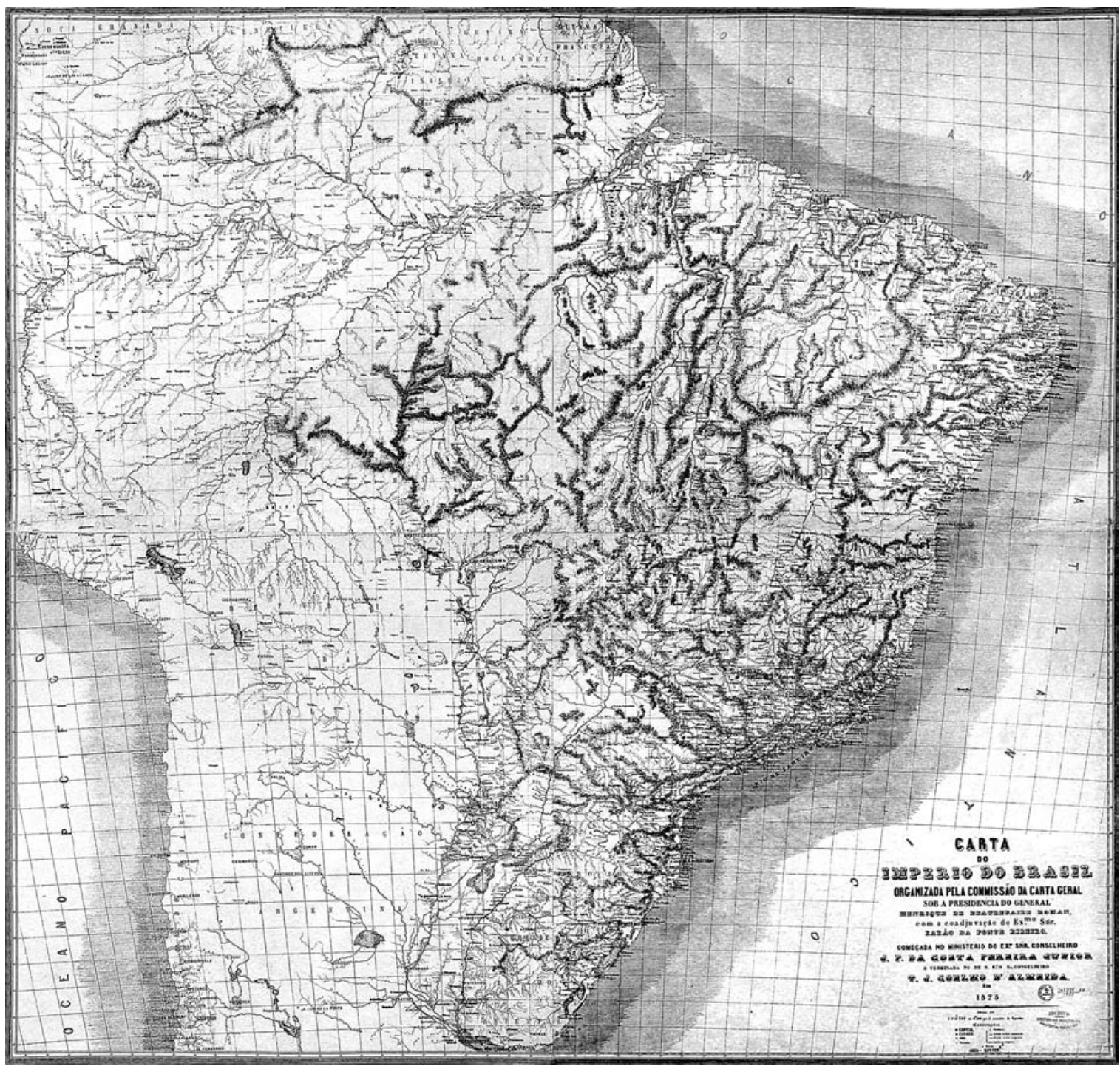

Fig. 1 Carta do Império do Brasil em 1875.

Fonte: Fotomontagem de Leonardo Rangel a partir das quatro folhas do mapa original fotografado na $5^{\text {a }}$ Divisão de Levantamento do Exército. 
Ao interpretar o mapa publicado em 1875, notamos a presença da cientificidade expressa no século XIX, que buscava a adoção de uma linguagem universal e da padronização dos meios de fazer e ler mapas. 0 mapa, em preto e branco, apresenta os territórios indígenas e o nome da etnia em questão, elementos representativos para hidrografia, relevo, estradas de ferro construídas e as que estavam planejadas para construção, e fronteiras internacionais que possuem pouco destaque. A questão do território indígena pode, também, ser interpretada sob a ótica do governo imperial em considerar o índio além das fronteiras dos países sul-americanos, como uma entidade "transterritorial". Dessa forma, incorporou-se essa peculiaridade nas discussões territoriais entre o Império Brasileiro e as repúblicas vizinhas. 0 desconhecimento dos territórios vizinhos ainda é bem aparente, com a ressalva do Paraguai, 0 que esclarece a opção da CCGl em demonstrar vazios cartográficos.

Ao observar o mapa de relance, temos a ideia de obstáculos. As cadeias de montanhas são desenhadas como muralhas, e as vias de transporte estabelecem-se visualmente em um segundo plano. Esta representação maciça do relevo em lugar da hidrografia em grande parte dos mapas do século XIX está arraigada nos conceitos geográficos de Philippe Buache (1700-1763), do século XVIII. Segundo o geógrafo Fábio Guimarães (1906-1979), a hipótese de Buache de que as cadeias de montanhas fossem sempre divisoras de águas influenciou profundamente o século XIX, e foi responsável por muitos erros na representação do relevo. ${ }^{43}$ Sobre isso, ele cita Delgado de Carvalho, que diz que grande parte dos mapas do final do século XIX está "caracterizada pelas extensas minhocas ou lacraias que representam a orografia e fecham hermeticamente as desejadas "bacias fluviais"'. ${ }^{44}$ Sendo assim, o país pode ser interpretado pelo imaginário social como intransponível, fechado, o que pode auxiliar na defesa e na afirmação do território nacional. Porém, pode dificultar o tão desejado movimento de imigrantes europeus para um país considerado "fechado".

Werneck e Krauss escreveram que "o país e o seu desenvolvimento material não têm acompanhado os progressos rápidos que têm mostrado na sua organização social", e ressaltaram a importância de "tornar conhecido tanto a nós como ao estrangeiro os elementos de nossa prosperidade". ${ }^{55}$ Para isso, devemos dominar a terra não somente pela ocupação agrícola ou industrial, mas pela imagem simbólica de um mapa. ${ }^{46}$ Nesse momento da criação da Carta Geral do Império, vemos que esta tem a se destacar como um símbolo de prosperidade e progresso da nação, o que talvez possa ser explicado pelos dois momentos de sua publicação: a Exposição Nacional de 1875 e a Exposição Universal de Filadélfia de 1876. ${ }^{47}$ Nesse instante, 0 uso de mapas para este fim já era utilizado no mundo afora, e observa-se que elementos estéticos tornam-se cada vez mais presentes, já que esses mapas já não são mais enrolados após seu uso, são expostos definitivamente. A percepção desse discurso civilizatório multiplica as iniciativas de incentivo à imigração europeia e norte-americana. A divulgação dessa imagem do Brasil torna-se uma possibilidade para novas frentes migratórias, representando o interesse da elite política como forma de solucionar o problema da falta de mãode-obra derivado de políticas abolicionistas.

A quarta Exposição Nacional, que ocorreu no ano de 1875, no qual a Comissão e seu presidente receberam diplomas, reuniu os produtos naturais e industriais produzidos no país. 0 tom de voz presente na época sugere uma exaltação à grandeza e à prosperidade da nação brasileira. Saldanha da Gama escreve um livro sobre alguns artigos expostos, e já em seu primeiro parágrafo trata o Brasil como o "colosso da América do Sul" e afirma que a Exposição é preparatória para a Universal de Filadélfia, o que se trata de "nada menos do que de envolver o nome da nossa pátria de todo 0 brilho de suas riquezas sem esquecer que agora, mais do que nunca, cumpre ao Brasil provar à luz do universo 0 grau de sua opulência, da sua força e da sua civilização" ${ }^{48}$ Esse documento simboliza a forma como 0 nacionalismo coloriu as iniciativas governamentais na segunda metade do século XIX e, mesmo que Gama somente tenha escrito sobre os produtos naturais, vemos, em seu discurso, o tom competitivo que ocorreu entre o Brasil e os Estados Unidos para se estabelecer como uma potência ex-colonial da América.

Os Estados Unidos, cedendo a seu amor próprio, querem ocupar o lugar mais distinto nas galerias da futura exposição universal. Exigem eles que o Império do Brasil ocupe o lugar que lhe compete como segunda potência da América; e a menos que a comissão superior e o governo Imperial não estendam as suas vistas para maior área de nossos produtos, receamos que 0 vasto país onde vimos a luz figure muito abaixo de sua posição real. ${ }^{49}$ 
Por meio dos relatos da Exposição Nacional de 1875, assim como de outras, serviu como um preparo para a Exposição Universal de Filadélfia em 1876, centenário dos Estados Unidos da América, foi possível retratar que não podemos considerar que o intuito da CCGI foi somente o de resolver os possíveis problemas de sucessão e legitimidade da demarcação de limites ocorridos ao longo dos séculos; nem que a Carta Geral do Império foi apenas mais um dos objetos figurados na Exposição de 1876 para firmar a participação do Brasil em atividades científicas de renome e precisão, o que simbolizaria o país como um polo de produção científica equiparável com países da Europa e dos Estados Unidos. Os objetivos da publicação de um mapa entram aqui como um dos elementos históricos essenciais para a compreensão da história cartográfica brasileira. Veremos ao longo do texto as circunstâncias que levaram a Comissão a seguir seu rumo, e como isso pode ser interpretado à luz da História da Ciência.

Os trabalhos decresceram após a finalização da versão para a Exposição Universal de 1876, o que tornou possível modificar a organização da CCGl em três seções: Desenho, responsável pelas cópias e reduções de diversos mapas; Triangulação, por finalizar o serviço; e Escrituração, que realizava a análise absoluta e relativa da exatidão dos instrumentos, e a "composição de tabelas que facilitassem as conversões e as correções das graduações de diferentes instrumentos".$^{50}$ Os resultados da CCGI não se limitaram à Carta Geral propriamente dita e à triangulação da corte, como já se demonstrou nesse texto. Os trabalhos de cópias e reduções eram efetuados desde o início, e foram intensificados após a publicação da versão reduzida em 1876. A partir dessas versões "procedeu a comissão a avaliação da área do Império, calculando sua superfície dos quadriláteros e frações dos quadriláteros em que dividiu a carta pelo traçado dos meridianos e paralelos distanciados de 30 minutos";51 chegando ao resultado de 8.337.218 quilômetros quadrados. Este resultado é uma das pouquíssimas menções da Carta Geral do Império no Diccionario historico, geographico e ethnographico do Brasil, que foi publicado no centenário da independência em 1922 pelo Instituto Histórico e Geográfico Brasileiro.

Curiosamente, a CCGI não teve um regulamento estabelecido, conforme Rohan escreveu no relatório final. ${ }^{52}$ Ao considerar isso, ele estabelece um projeto de regulamento, do qual nenhuma deliberação foi tomada. Nesse projeto, Rohan estabelece que a comissão organizou a carta e a descrição geográfica do Brasil; para isso, deveria apresentar um plano para realizar essa meta do modo mais rápido e barato possível. A nova comissão, que se chamaria Comissão de trabalhos geográficos do Império, teria uma índole instrutiva mais evidente, de modo a instruir os alunos nas práticas geodésicas; fazer análise das obras de cosmografia e geografia que forem publicadas com destino à instrução pública; e organizar, para o uso das escolas de instrução elementar, um sistema de definições geográficas. Dessa forma, segundo a visão de Beaurepaire Rohan, se estaria preparando uma futura geração de astrônomos e engenheiros habilitados a desenvolver uma carta nacional mais apurada. Beaurepaire Rohan admitia que estivesse "reconhecida a impossibilidade de empreendermos uma triangulação que abranja a vasta extensão do nosso território, (...), outro devia ser 0 alvitre a que tínhamos de recorrer, para melhorar a carta do nosso país". ${ }^{33}$ Sendo assim, no relatório final, desenvolveu o projeto de uma carta arquivo para preparar materiais para uma futura nova carta.

0 fim da Comissão da Carta Geral do Império em 1878, e das outras comissões paralelas, abordadas anteriormente, confirmou um despreparo administrativo e cultural frente à importância da Cartografia, o que se agrava ainda mais com a sangria dos cofres públicos ainda referentes aos gastos com da Guerra do Paraguai. A pressão econômica é sentida internamente pelo governo, e, após discussões, acharam pertinente uma maior contenção de gastos e extinguir tais comissões.

Em aviso $n^{o} 6$ de 2 de Março próximo passado, comunicou-me S. Ex. o Sr. conselheiro João Lins Vieira Cansansão de Sinimbú, ministro e secretário de estado dos negócios da agricultura, comércio e obras públicas, ter resolvido extinguir a Comissão da Carta Geral do Império, a meu cargo, por ser contrária às circunstâncias financeiras atuais à conservação de serviços que não são urgentes. ${ }^{54}$

Com o término dessas comissões, as atividades cartográficas se limitaram em relação à área e interesse, como as Comissões Geográficas de São Paulo (1886) e de Minas Gerais (1891), e os planos ferroviários de iniciativa privada. 
0 fim do Império estava próximo. Na República, as iniciativas de porte nacional reaparecem nas mãos dos militares com a criação da Comissão da Carta Geral do Brasil, em 1903. No entanto, o sonho de um mapa nacional que satisfaça as dimensões brasileiras, os critérios territoriais e científicos, se realiza somente em 1922 com a Carta Geográfica do Brasil, em comemoração ao centenário da Independência. Em todas essas entidades, a presença da CCGI aparece em citações diminutas em rodapés, ou em relatórios técnicos. Mas em nenhuma delas foi reconhecido o principal objetivo a que foi destinada a Carta do Império: a representação de progresso e civilização em território nacional e internacional; motivo pelo qual tenha sido posta em segundo plano por diversas áreas da historiografia brasileira.

\section{Considerações finais}

A imagem de um mapa está associada a um domínio do território, tornando-o elemento ímpar nas simbologias de progresso e civilização. Aos olhos do brasileiro, o sentimento é de unidade, de nação; do ponto de vista do estrangeiro, 0 Brasil está "domesticado" e preparado para a chegada de seu braço trabalhador. A presença nas Exposições de 1875 e 1876, em conjunto com os produtos agrícolas e industriais criados aqui, buscava, também, afirmar a participação do Brasil em atividades científicas, equiparando-o com países europeus e Estados Unidos. A Carta Geral do Império possuiu necessidades externas a ela, já que houve um momento em particular no qual se aceitou o fato de publicar um mapa que não satisfazia todas as exigências administrativas. Utilizando recursos estéticos para sua confecção, e não somente uma instrumentação científica; longe de ser um produto finalizado, a Carta Geral do Império tornou-se um marco, um divisor de águas, juntamente com o funcionamento integral de sua Comissão.

0 interesse do Ministério da Agricultura também era econômico, como foi observado nas comissões que ocorreram paralelamente à CCGI. Como a principal atividade econômica do país se concentrava na produção agrícola, e em parte na mineração, os resultados dessas comissões contribuíram do ponto de vista geológico e de transportes; 0 que acabou por contribuir com a expansão dessas atividades pelo território nacional. 0 modelo de um desses empreendimentos, a Comissão Geológica, provou sua importância ao ser copiado em duas outras atividades anos depois.

Mesmo que o fim da Comissão seja explicado pelas dificuldades monetárias imperiais do final da década de 1870, devido à Guerra do Paraguai e à economia agrária, não podemos deixar de lado a importância da morte do Barão da Ponte Ribeiro um mês antes. Seu mapa não conseguiu o principal objetivo de ser uma carta exata do território brasileiro. No entanto, a Comissão se enquadra como centralizadora das atividades cartográficas desse período, assim como um marco temporal, o embrião para futuras atividades cartográficas. Teve como participantes diversos personagens da História da Ciência no Brasil, como Liais, Cruls, Pereira Reis, Teste, Moraes Rego, entre outros, e pode ser vista como um ponto de convergência com os mapas do passado e as iniciativas que serão realizadas nos períodos futuros.

\section{Notas e Referências Bibliográficas}

Bruno Rangel Capilé de Souza é mestre em História das Ciências das Técnicas e Epistemologia pela Universidade Federal do Rio de Janeiro (UFRJ) e bolsista MAST - PCI/MCTI. E-mail: brcapile@gmail.com.

Moema de Rezende Vergara é doutora em História Social da Cultura pela Pontifícia Universidade Católica do Rio de Janeiro (PUC-Rio), professora do Programa de Pós-Graduação em Museologia e Patrimônio da UNIRIO/MAST e pesquisadora titular do MAST. E-mail: moema@mast.br.

1 HARLEY, J. B. The new nature of maps: Essays in The History of Cartography. Baltimore, The Johns Hopkins University Press, 2001. p. 39.

2 Para Jaime Cortesão a CCGI se formou em 1864, informação que provavelmente veio dos relatórios do MACOP de 1869 e 1870; e trabalhos mais recentes, como os de Manoel de Sousa Neto, e Paulo Menezes e Alan Graça, indicam o ano de 1862. CORTESÃO, Jaime. Curso de História da Cartografia Política do Brasil. Instituto Rio Branco, 1945. Ver também FADEL, Simone. Meio ambiente, saneamento e Engenharia no período do Império à Primeira República: Fábio Hostílio de Moraes Rego e a Comissão Federal de Saneamento da Baixada Fluminense. Tese (Doutorado em História Social) - , Universidade de São 
Paulo, 2006. MENEZES, Paulo Márcio Leal de; GRAÇA, Alan José Salomão. Cartography of the Empire of Brazil. In: INTERNATIONAL SYMPOSIUM ON THE HISTORY OF CARTOGRAPHY, 3. 2010, Arlington. Proceedings... Arlington, USA: University of Texas, 2010. NETO, Manoel Fernandes de Sousa. A Comissão de Triangulação do Município da Corte. In: LOIS, Carla (Org). Imágenes y lenguajes cartográficos en las representaciones del espacio y del tiempo: I Simposio Iberoamericano de Historia de la Cartografia. Buenos Aires: Universidade de Buenos Aires, 2006.

3 ADONIAS, Isa. A Carta Geral do Império do Brasil, de 1875: Trabalhos que a antecederam, sua elaboração e contribuição do Barão Duarte da Ponte Ribeiro. In: CORTESÃO, Jaime. História da Cartografia Política do Brasil. Instituto Rio Branco, Rio de Janeiro, 1945. Mimeografado.

4 HARLEY, 2001, op. cit., p. 37.

5 HARLEY, 2001, op. cit., p. 39

6 Conrado Jacob de Niemeyer (1788-1862), militar formado, sai de Portugal por causa da invasão francesa e é incorporado ao exército da Corte Portuguesa no Brasil, no regimento de artilharia. Depois de dois julgamentos militares por abusos e arbitrariedades, Niemeyer pede reforma em 1833 e exerce a função de engenheiro em diversas comissões. Candido Mendes de Almeida (1818-1881) é normalmente reconhecido pela sua atuação nas áreas políticas e de direito, na qual se formou bacharel na faculdade de Olinda. Sua preocupação na instrução em Geografia e História, presente em sua obra Atlas do Império do Brazil (1868), também foi expressa nos catorze anos em que lecionou essas disciplinas no Lyceo de São Luís. TELLES, Pedro Carlos da Silva. História da Engenharia no Brasil. Rio de Janeiro: Clavero, 1994; BLAKE, Augusto V. A. S. Diccionario bibliographico Brazileiro. Rio de Janeiro, Imprensa Nacional, 1893. v. 2.

7 Conforme o decreto $n^{0} 2748$ de 16 de fevereiro de 1861.

8 WERNECK, Hermenegildo Luiz dos Santos; KRAUSS, Carlos. Apontamentos relativos às explorações no Império. Brasil: Ministério da Agricultura, do Comércio e das Obras Públicas, 1866. (Relatório do Ministério da Agricultura, do Comércio e das Obras Públicas.)

9 PEIXOTO, Renato Amado. A Carta Niemeyer de 1846 e as condições de leitura dos produtos cartográficos. Anos 90, Porto Alegre, v. 11, n. 19/20, p. 299$318,2004$.

10 Ibidem

11 RIBEIRO, Duarte da Ponte. Exposição dos trabalhos históricos, geográficos e hidrográficos que serviram de base à Carta Geral do Império exibida na Exposição Nacional de 1875. Rio de Janeiro: Typographia Nacional, 1876. p. 1.

12 Henrique de Beaurepaire Rohan (1812-1894) teve uma atuação notória na História do Brasil, incentivada pela proximidade de sua família com a Corte, tornando-se amigo e conselheiro de Dom Pedro II. Desempenhou em diversas comissões científicas ou militares (como a Guerra do Paraguai), foi presidente das províncias do Pará e Paraíba e diretor de obras do município neutro, onde fez uma reforma urbanística na década de 1840. BLAKE, Augusto V. A. S. Diccionario bibliographico brazileiro. Rio de Janeiro: Imprensa Nacional, 1895. v. 3. Mas, sua maior contribuição foi nos trabalhos de levantamentos geográficos e cartográficos, exploração fluvial, traçado de estradas e planejamento urbano. TELLES, 1994, op. cit.

13 ROHAN, Henrique de Beaurepaire. Relatório final da Comissão da Carta Geral do Império. Rio de Janeiro: Typographia Nacional, 1878.

14 ROHAN, Henrique de Beaurepaire. Relatório da Comissão da Carta Geral do Império. Brasil: Ministério da Agricultura, do Comércio e das Obras Públicas, 1866. (Relatório do Ministério da Agricultura, do Comércio e das Obras.)

15 ROHAN, op. cit., 1878 p. 51

16 A aventura de Hartt se inicia quando é convidado para estudar com o zoólogo e geólogo Louis Agassiz (1807-1873) em 1863 no Museu de Zoologia Comparativa de Cambridge. A dedicação resultou em um convite de Agassiz para compor a equipe de naturalistas da Thayer Expedition em 1865, viagem que resultou no livro Geology and physical Geography of Brazil (1870), assim como influenciou os modelos da Comissão Geográfica e Geológica de São Paulo (1886) e o Serviço Geológico e Mineralógico do Brasil (1907), ambos dirigidos pelo geólogo Orville Derby.

17 FIGUEIRÔA, Silvia Fernanda de Mendonça. As Ciências Geológicas no Brasil: uma história social e institucional, 1875-1934. São Paulo: Ed. HUCITEC, 1997.

18 BRASIL. Relatório do Ministério da Agricultura, do Comércio e das Obras Públicas. 1875. p. 220.

19 BRASIL. Primeiro Relatório do Ministério da Agricultura, do Comércio e das Obras Públicas, 1877

20 A determinação da longitude pela eletricidade já havia sido feita na França, pois sabiam-se que as longitudes geodésicas nem sempre concordam com as longitudes referidas a vertical verdadeira do lugar, fornecida pelos processos astronômicos. Ela foi apresentada ao Instituto de França por Pedro II, quando este se encontrava em Paris.

21 Esse sistema luminoso foi reconhecido pelo Instituto de França e por outras corporações científicas, por ser mais exato do que o empregado com os fios telegráficos, por causa do tempo que gasta a eletricidade em carregar a linha, o que bem pode não ser o mesmo nos dois sentidos; ao passo que 0 tempo gasto em transmitir-se a luz de um ponto ao outro é conhecido.

22 LIAIS, Emmanuel. Ofício no 2 do Imperial Observatório do Rio de Janeiro de 11 de janeiro de 1876 para Manuel Buarque, chefe da Diretoria de Obras Públicas. Comissão astronômica: ofícios e relatório da comissão. Rio de Janeiro: Arquivo Nacional, 1876. (Figitalização do microfilme 002-000-83.)

23 REIS, Manoel Pereira dos. Comissão Astronômica do Ministério da Agricultura: $1^{\text {a }}$ Operação - Determinação de latitude e de longitude entre o Imperial Observatório Astronômico do Rio de Janeiro e a Barra do Pìrahy. Rio de Janeiro: Typographia Nacional, 1877.

24 Cf. OLIVEIRA, J. T. de; VIDEIRA, A. A. P. As polêmicas entre Manoel Pereira Reis e Emmanuel Liais e Luiz Cruls na passagem do século XIX para o século XX. Revista da SBHC, n. 1, p. 42-52, 2003.

25 BRASIL. Relatório do Ministério da Agricultura, do Comércio e das Obras Públicas, 1878. p. 236.

26 ROHAN, op. cit., 1875, p. 27

27 MORIZE, Henrique. Observatório Astronômico: Um Século de História (1827-1927). Rio de Janeiro: MAST: Salamandra, 1987.

28 ROHAN, Henrique de Beaurepaire. Estudos acerca da organização da Carta Geographica e da Historia Physica e Politica do Brazil. Rio de Janeiro: Typographia Nacional, 1877. (Biblioteca de Obras Raras CT/UFRJ.)

29 WERNECK, Hermenegildo Luiz dos Santos; KRAUSS, Carlos. Apontamentos relativos às explorações no Império. Brasil: Ministério da Agricultura, do Comércio e das Obras Públicas, 1866. (Relatório do Ministério da Agricultura, do Comércio e das Obras Públicas.) 
Antes de trabalhar na elaboração da Carta Geral, Ernesto José Carlos Vallée trabalhou anos na província de Goiás como administrador de obras públicas, inspetor geral dos presídios, e, em especial, nos levantamentos de cartas hidrográficas. NASCIMENTO, Patrícia Emanuelle. Elites políticas e projetos de integração em Goiás (1822-1855). Dissertação (mestrado em História das Sociedades Agrárias) — . Programa de Pós-Graduação da Universidade Federal de Goiás. Goiânia, 2003.

31 BRASIL. Relatório do Ministério da Agricultura, do Comércio e das Obras Públicas, 1868. p. 120.

32 João Martins da Silva Coutinho (1831-1889) engenheiro militar, dedicou-se a trabalhos de exploração geográfica, geológica, paleontológica e botânica na Bacia Amazônica, sendo considerado por Silva Telles o maior explorador da Amazônia, na qual percorreu, de 1851 a 1865, vários rios e trechos nunca visitados pelos homens "civilizados". Representou o Brasil nas Exposições Universais de Paris (1867) e Filadélfia (1876). TELLES, op. cit.

33 BRASIL. Relatório do Ministério da Agricultura, do Comércio e das Obras Públicas, 1871.

34 BRASIL. Relatório do Ministério da Agricultura, do Comércio e das Obras Públicas, 1870. p. 175.

35 BRASIL. Relatório do Ministério da Agricultura, do Comércio e das Obras Públicas, 1872.

36 ROHAN, op. cit., 1875.

37 ROHAN, op. cit., 1875, p. 9.

38 BRASIL, op. cit., 1872, p. 73.

39 BRASIL, op. cit., 1871, p. 163.

40 ABBADIE, Antoine. Geographie de L'Ethiopie: Ce que j'ai entendu, faisant suite a ce que j'ai vu. Paris: Gustave Mesnil Ed.,1890.

41 BRASIL. Relatório do Ministério da Agricultura, do Comércio e das Obras Públicas, 1877. p. 338.

42 ROHAN, op. cit., 1875, p. 9.

43 GUIMARÃES, Fábio de Macedo Soares. Observações sobre o Problema da Divisão Regional. Revista Brasileira de Geografia, n. 3, ano XXV, p. 289-311, 1963.

44 DELGADO DE CARVALHO, Carlos. Metodologia do ensino geográfico. Rio de Janeiro: Livr. Francisco Alves, 1925. p. 75 apud GUIMARÃES, Fábio de Macedo Soares. Observações sobre o problema da divisão regional. Revista Brasileira de Geografia. Ano XXV, nº 3, jul-set, p. 289-311, 1963.

45 WERNECK; KRAUSS, op. cit., 1866, p. 1.

46 Ibidem.

470 mapa exposto na Exposição Universal da Áustria em 1873 foi feito por Pedro Torquato Xavier de Brito, que reduziu e corrigiu às pressas o mapa de Conrado Niemeyer de 1846 para a figuração de um mapa nessa exposição.

48 GAMA, José Saldanha da. Estudos sobre a Quarta Exposição Nacional de 1875. Rio de Janeiro: Typographia Central de Brown \& Evaristo, 1876. p. 7..

49 GAMA, op. cit., p. 11 (itálicos de Gama).

50 BRASIL, op. cit., 1877, p. 342.

51 BRASIL, op. cit., 1877, p. 339.

52 ROHAN, op. cit., 1878.

53 ROHAN, op. cit., 1878, p. 5.

54 ROHAN, op. cit., 1878, p. 3.

[ Artigo recebido em 10/2011 | Aceito em 04/2012 ] 